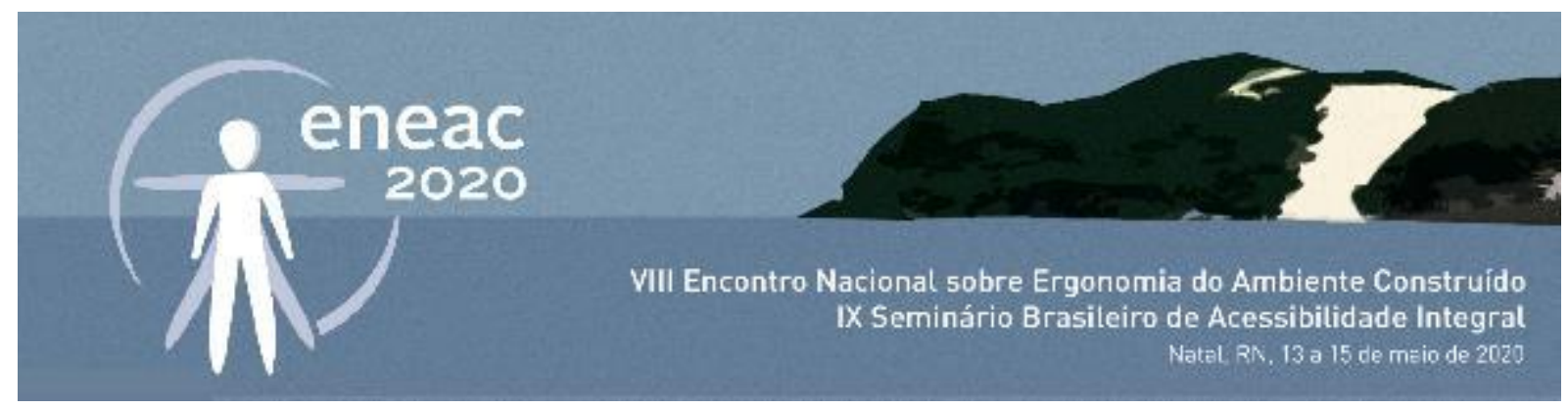

\title{
Acessibilidade criativa: A relação da NBR 9050 com ações criativas no processo de projeto
}

\section{Creative accessibility: The relationship of NBR 9050 with creative actions in the design process}

\author{
NATHALIA BOCAYUVA DE CARVALHO \\ Arquiteta, UFRN, natybocayuva@hotmail.com
}

ANNA PAULA SANTOS EMERENCIANO

Arquiteta, UFRN, annapaulaemerenciano@hotmail.com

\section{RESUMO}

Atualmente exige-se que espaços públicos e de uso comum devam ser acessíveis para todos e, para isso, devem seguir normas vigentes que ditam as melhores condições de locomoção e uso destes espaços por pessoas com deficiência e/ou mobilidade reduzida. Essas exigências influenciam diretamente a concepção do espaço por arquitetos e designers, pois estes grupos de pessoas têm necessidades específicas que devem ser consideradas ao longo do processo de projeto. Para normatizar esta questão, foi criada a NBR 9050, vigente no Brasil, que define as diretrizes e parâmetros técnicos que devemos observar na hora de projetar, sejam edificações, mobiliário, espaços e equipamentos urbanos. Observa-se que estas diretrizes acabaram engessando as soluções projetuais e gerando resultados com falta de criatividade e inovação. A situação fica pior quando precisam ser feitas adaptações ao projeto original, onde normalmente se exige a funcionalidade, porém a qualidade estética é abandonada. $\mathrm{O}$ objetivo deste artigo é discutir como a norma vigente de acessibilidade (NBR 9050) influencia o processo de projeto e a presença de ações criativas.

PALAVRAS-CHAVE: acessibilidade; criatividade; processo de projeto; NBR 9050

\section{ABSTRACT}

Currently, it is mandatory that public and common use spaces must be accessible to all and, for that, they must follow current rules that dictate the best conditions for locomotion and use of these spaces by people with disabilities and / or reduced mobility. These requirements directly influence the design of the space by architects and designers, as these groups of people have specific needs that must be considered throughout the design process. To standardize this issue, NBR 9050 was created in Brazil, which defines the guidelines and technical parameters that we must observe when designing buildings, furniture, spaces and urban equipment. It is observed that these guidelines ended up plastering the design solutions generating results with a lack of creativity and innovation. The situation becomes 


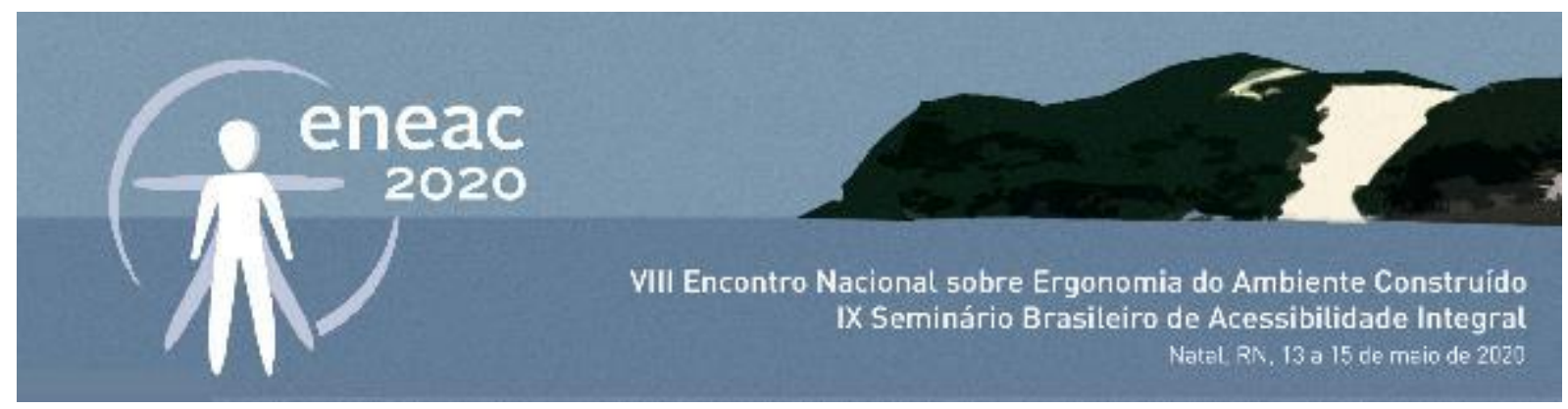

worse when adaptations to the original project need to be made, where functionality is normally required, but aesthetic quality is abandoned. The purpose of this article is to discuss how the current accessibility standard (NBR 9050) influence the design process and the presence of creative actions.

KEYWORDS: accessibility; creativity; design process; NBR 9050

\section{INTRODUÇÃO}

Na pesquisa do Censo 2010 (IBGE, 2010) foi constatado que 45,6 milhões dos brasileiros possuem algum tipo de deficiência - seja ela visual, motora ou auditiva, com diferentes graus de severidade - 0 que corresponde a cerca de $23 \%$ da população total. Ainda, de acordo com dados do Censo 2010 (IBGE, 2010), cerca de 10,47\% da população brasileira possui 60 anos ou mais. Em dados mais recentes, fornecidos pelo banco mundial, foi registrado em 2018 uma média de 76,3 anos de expectativa de vida da população.

Os dados acima retratam dois grupos da população, idosos e pessoas com deficiência, que necessitam de condições apropriadas para realizar funções básicas de seu cotidiano. "Geralmente as pessoas com maiores dificuldades em executar atividades em ambientes, principalmente as pessoas com deficiência, ficam à margem da sociedade. Muito disso se deve ao fato desses ambientes não auxiliarem as pessoas amenizando suas dificuldades" (MORAES, 2007).

Sendo assim, ao projetar um ambiente, o arquiteto deve levar em consideração que os espaços precisam ser adequados para todos os usuários prevendo nos projetos a igualdade, universalidade, segurança e autonomia para todos, conforme determinam as normas vigentes de acessibilidade.

A arquitetura é ainda um ato de criar, que envolve arte e técnica projetual de edificações e ambientes. É uma atividade de concepção onde espera-se um resultado funcional e criativo. A criatividade está presente no cotidiano e na história dos humanos, nas diferentes áreas de conhecimento. Atualmente empresas e organizações, cada vez mais, buscam por tal diferencial, "isso possivelmente se deve às características do atual momento da história, marcado por mudanças em ritmo acelerado, complexidade e incerteza, em meio a um impressionante processo de globalização e competição empresarial sem precedente" (ALENCAR,2009). O objetivo deste artigo é discutir como as normas vigentes de acessibilidade influenciam o processo de projeto e a presença de ações criativas.

\section{TODOS A INCLUSÃO}

O conceito de acessibilidade de forma simples significa "aquilo que tem acesso fácil". Tal definição é contraditória em relação a grande dificuldade que as pessoas com deficiência e/ou mobilidade reduzida se deparam diariamente diante das diversas barreiras - sejam físicas ou até atitudinais impostas, especialmente se pensarmos do ponto de vista de arquitetura.

Por definição da própria NBR 9050:2015 o termo acessibilidade significa: 


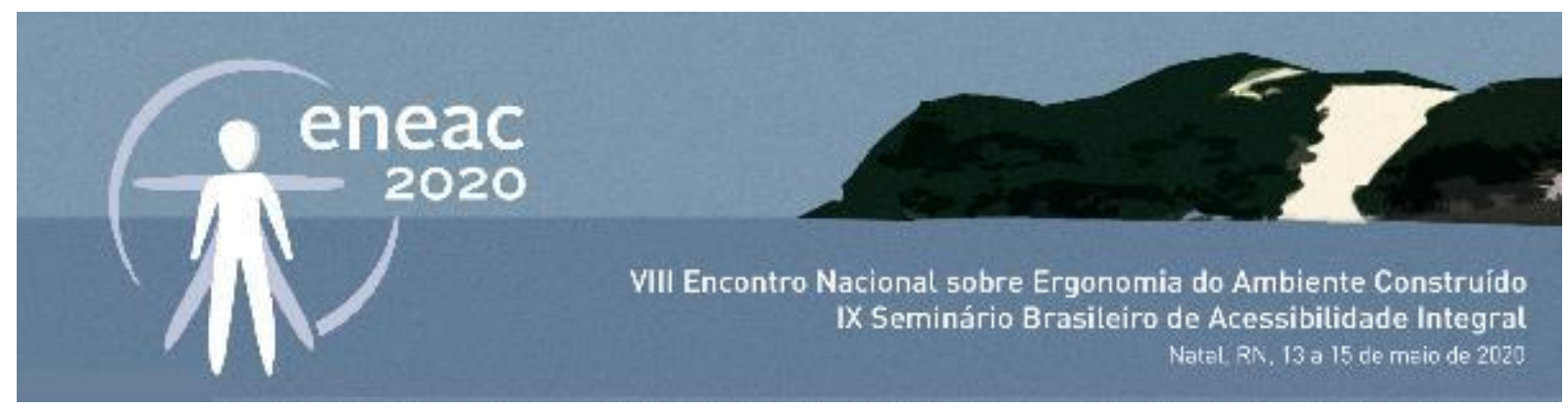

\begin{abstract}
"Possibilidade e condição de alcance, percepção e entendimento para utilização, com segurança e autonomia, de espaços, mobiliários, equipamentos urbanos, edificações, transportes, informação e comunicação (..) por pessoa com deficiência física ou mobilidade reduzida". (ABNT, 2015).
\end{abstract}

A aplicação da acessibilidade na arquitetura é orientada através de normas técnicas, que regulam dimensões e especificações com a finalidade de estabelecer parâmetros e critérios. Estes orientam a produção dos projetos de arquitetura visando proporcionar para todas as pessoas independentemente de suas condições físicas e/ou mentais, da sua idade ou das suas limitações - a utilização dos espaços de forma autônoma, segura e com independência.

A produção dessas normas é de responsabilidade da Associação Brasileira de Normas Técnicas (ABNT) e tem o objetivo de padronizar as técnicas de produção no país, sendo fundamental para orientar e estabelecer diretrizes.

"As Normas Brasileiras, cujo conteúdo é de responsabilidade dos Comitês Brasileiros (ABNT/CB), dos Organismos de Normalização Setorial (ABNT/ONS) e das Comissões de Estudo Especiais (ABNT/CEE), são elaboradas por Comissões de Estudo (CE), formadas pelas partes interessadas no tema objeto da normalização. Para seu desenvolvimento são formados os Comitês Brasileiros (CB)". (ABNT, 2015).

A primeira versão da norma de acessibilidade, a NBR 9050, atualmente intitulada de Acessibilidade a Edificações, Mobiliário, Espaços e Equipamentos Urbanos, foi desenvolvida no ano de 1985. Foi então, na década de 80 , que as discussões no Brasil sobre acessibilidade se tornaram mais fortes, alinhadas com a promulgação da Constituição Federal 1988 que estabeleceu assistência de educação a 'pessoas excepcionais'.

Sendo assim, a NBR 9050, que teve sua primeira versão em 1985, apresentou três revisões posteriores, sendo a primeira no ano de 1994, uma no ano de 2004, outra no ano de 2015, a qual está em processo de revisão. Um grande ponto que se pode destacar na versão da NBR 9050, atualmente vigente, são as apliçações mais efetivas na norma dos princípios do desenho universal. Destaca-se que nas versões anteriores, mais especificamente a partir da versão de 1994, o termo desenho universal já estava presente - fato compatível com o momento histórico, já que o conceito desenho universal foi elaborado por Ron Mace em 1985, levando ainda um tempo para disseminação no Brasil.

Na versão de 2004 a norma pareceu já ter agregado mais o uso do termo: "ao menos no que diz respeito aos conceitos e definições: o enfoque teórico na pessoa com deficiência não existe mais e o ambiente acessível passa a ser considerado como benéfico a todos, independente de habilidades e limitações", mas "a ideia não parece refletir-se integralmente no conteúdo da norma" (MORAES, 2007).

Já na versão de 2015, não apenas o conceito de desenho universal aparece de forma mais clara, como também todos os seus princípios, que passaram inclusive a ser um anexo informativo à norma. $O$ que deixa bem claro que os espaços devem ser pensados e concebidos para que todas as pessoas possam utilizá-lo com segurança e conforto independente de suas capacidades, devendo os projetistas aplicarem os conceitos de desenho universal integralmente aos itens da norma.

Apesar da NBR 9050 ser a referência básica que direciona o projeto de arquitetura, existem várias outras normas que complementam seus parâmetros como por exemplo a NBR 16537:2016 -

Sinalização tátil no Piso, e a NBR 14718:200 - Guarda-corpos para edificação. Então, para desenvolver um projeto contemplando os itens de acessibilidade, é necessário entender um conjunto de normas e leis. Porém, devido a estruturação da NBR 9050 ser por eixos temáticos, em alguns casos se 


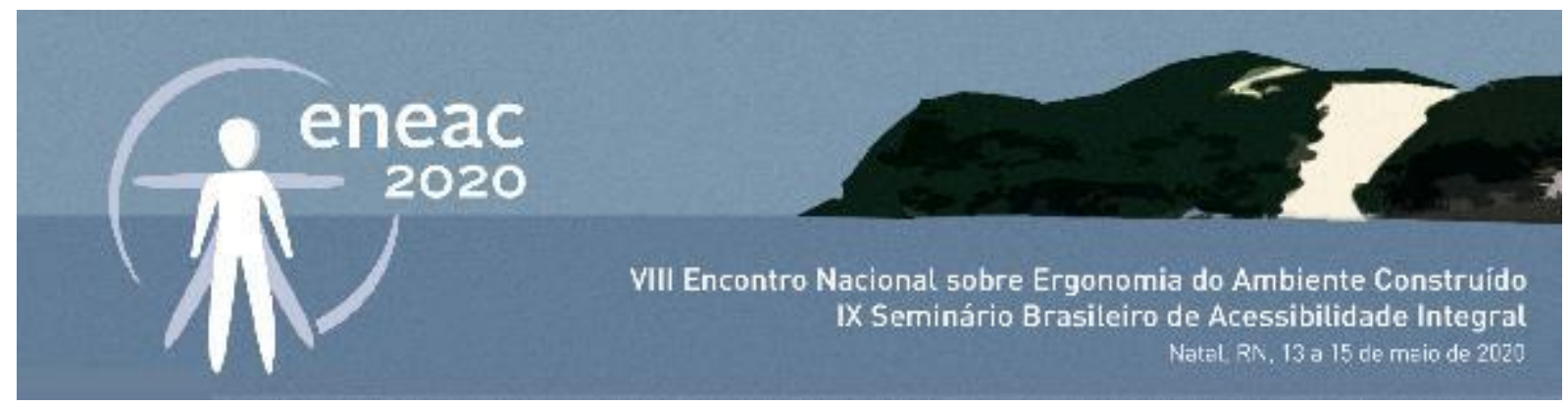

complementam com outras normas, causando uma maior dificuldade para o seu entendimento e consequente aplicação dos seus parâmetros nos projetos.

Nesses últimos 35 anos, os estudos em acessibilidade e os processos de conscientização das necessidades das pessoas com deficiência e/ou mobilidade reduzida se tornaram ainda mais intensos. Um novo marco foi determinado com a promulgação da Lei 13.146:2015 que instituiu a Lei Brasileira de Inclusão da Pessoa com Deficiência, "destinada a assegurar e a promover, em condições de igualdade, o exercício dos direitos e das liberdades fundamentais por pessoas com deficiência, visando a inclusão social e a cidadania" (BRASIL, 2015).

Com a promulgação da lei e a citação direta das normas de acessibilidades vigentes, a NBR 9050 e as demais normativas relacionadas à acessibilidade passaram a vigorar com valor de lei, como citado no artigo 57 da Lei 13.146:2015: “As edificações públicas e privadas de uso coletivo já existentes devem garantir acessibilidade à pessoa com deficiência em todas as suas dependências e serviços, tendo como referência as normas de acessibilidade vigentes".

A NBR 9050 se tornou então não só uma conscientização de inclusão das pessoas com deficiência e/ou mobilidade reduzida e passou a ter um grande embasamento técnico e jurídico. Porém, como MORAES (2007) destaca:

\begin{abstract}
"Apesar da existência do arcabouço técnico e jurídico para a acessibilidade no ambiente construído, e de toda a campanha de conscientização da população dos benefícios de um ambiente acessível e da necessidade da acessibilidade, principalmente para a inclusão social, ainda são poucas as entidades de ensino superior, mais especificamente nos cursos voltado à construção civil como arquitetura e engenharia civil, que trazem o tema em sua grade curricular. Sendo assim, são poucos os profissionais qualificados para projetar um ambiente acessível" (MORAES, 2007).
\end{abstract}

Algumas universidades do país perceberam a relevância do tema e criaram uma disciplina única voltada para acessibilidade nos cursos de arquitetura, como por exemplo, em 1996, "CAU-UFRN optou por criar uma disciplina optativa específica visando ampliar a sensibilização dos estudantes quanto às dificuldades das pessoas portadoras de deficiência" (ELALI, 2004), com o intuito de conscientizar os alunos (e futuros profissionais) sobre a importância de se eliminar as barreiras físicas para a inclusão social deste grupo de indivíduos, além de uma formação mais concreta deste conhecimento. Elali (2004) completa que ela deve ser tratada como uma temática trans-disciplinar, assim presente em diversas atividades de formação.

Entretanto, o caso citado acima não é o padrão entre as universidades do país. Existe a falta de valorização do tema que reflete na má transmissão do conteúdo para os alunos. Porém, acredita-se que isso está em processo de melhoria com a implantação da lei brasileira de inclusão que exige a inclusão de orientações temáticas relacionados ao desenho universal nas diretrizes curriculares do ensino superior. Desta forma, espera-se que os cidadãos e estudantes tenham mais familiaridade com as necessidades e carências deste grupo de indivíduos.

\title{
3 INOVADORES E ÚNICOS
}

A definição de criatividade de acordo com Gero e Maher (1993) é a introdução de novas variáveis a algo onde inicialmente não foram consideradas. Portanto para ser considerado criativo, o projeto precisa acrescentar algo a mais do que já existe. Entretanto, Lubart (2007) vem ressaltar que "a 


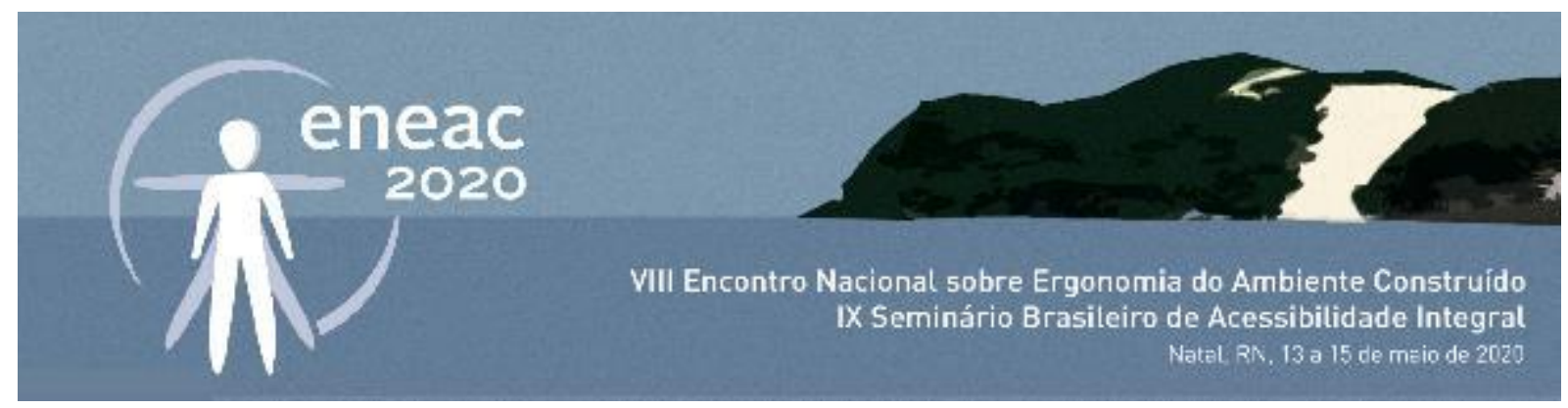

novidade, qualquer que seja seu ponto de referência, não é única ou suficiente para dar um caráter criativo a uma conduta", além disto, ela precisa trazer alguma relevância apropriada a uma dada situação (ALENCAR, 1996).

A sociedade espera que os profissionais que trabalham no meio criativo apresentem um talento nato para inovação (ALENCAR, 1996). Contudo a noção de criatividade mostra uma evolução da perspectiva espiritualista para uma noção mais racional e cientifica, entendendo-se que o potencial criativo deve 'florescer' a partir da experiência, desenvolvendo uma 'lógica subconsciente' (BARKI apud OLIVEIRA et al, 2009, p.123). O potencial criativo deixou de ser valorizado pelo momento Eureka!' e foi entendida a importância de todos os elementos que interferem no processo projetual, desde elementos externos as memórias cognitivas do projetista.

A biografia sobre criatividade é extensa e engloba as mais diversas áreas de estudo. Até os anos 1970, o foco das pesquisas era no indivíduo criativo como definidor do processo criativo. Porém, observouse que o processo criativo passa a sofrer influencias de outros componentes, os quais são os principais definidores das realizações criativas, como variáveis cognitivas, motivação, conhecimento, confiança, e variáveis ambientais, elementos culturais, socioeconômicos e educacionais (AMABILE, 1983).

Qualquer pessoa pode ser considerada criativa, contudo, quando uma pessoa não é estimulada ou exposta a um contexto que propicie ações inovadoras, dificilmente ela irá se tornar criativa (CSIZENTMIHALYI, 1996). Atualmente, observa-se uma realidade nos cursos de graduação de arquitetura que não favorece esse estímulo: "algumas pesquisas têm revelado que grande parte dos docentes desconhecem o tema criatividade, os livros sobre o assunto, os exercícios criativos, pois a maioria dos cursos formadores de professores não tem disciplina que enfoque essa área" (SANTOS, 2017). A falta deste incentivo durante a graduação reflete o processo de projeto do futuro profissional o qual este aluno irá se transformar.

A Carta UIA/UNESCO de Formação da Arquitetura (2011) defende que os educadores devem preparar os arquitetos para serem capazes de desenvolver novas soluções para o presente e para o futuro, porque o novo tempo trará importantes e complexos desafios em decorrência da degradação social e funcional em muitos assentamentos humanos. Contudo, não é isso que está acontecendo, a criatividade não é normalmente um tema debatido em sala de aula: "nos Cursos de Arquitetura pouco se fala sobre o que é criatividade, o que é o processo criativo, e como as heurísticas poderiam ser sistematicamente debatidas, estimuladas e aplicadas na prática de projeto". (FLORIO, TAGLIARI, 2009)

A evolução das pesquisas buscou entender como o processo criativo é estimulado, e concluiu que sua obra não poderia ser atribuída apenas a um singular conjunto de habilidades e a personalidade do autor, também deveriam levar em consideração os elementos do meio em que a pessoa está inserida (HENNESEY; AMABILE, 1988). Além disso, quanto mais conhecimento e intimidade com a importância da criatividade no meio profissional, mais se procura incluir ações e metodologias que incentivem o processo criativo a alcançar os objetivos e resultados propostos. E em especial na arquitetura, 


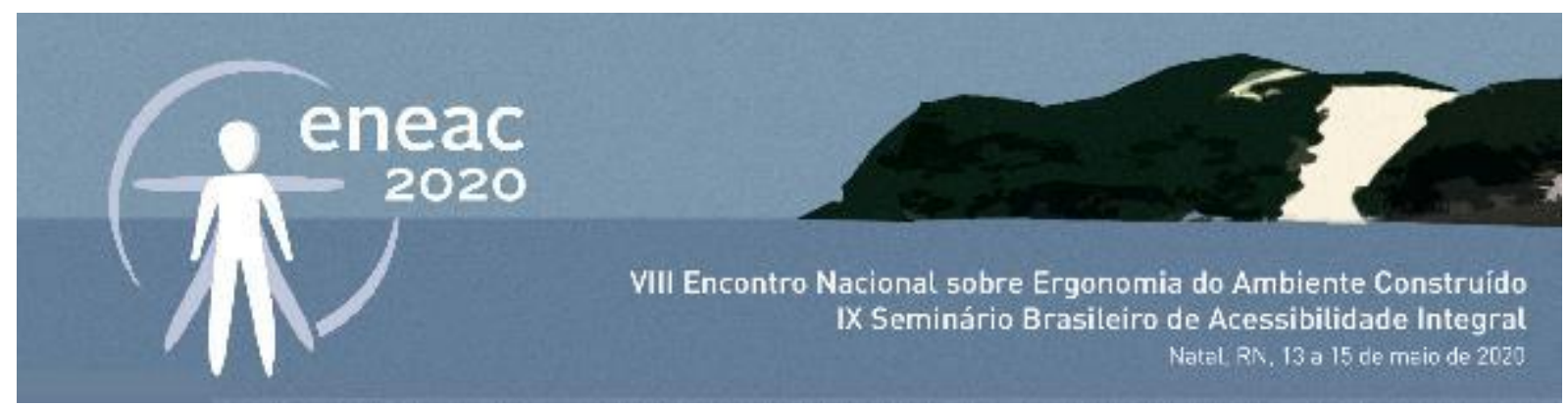

Martinez (2000) vem relembrar que o projeto é uma atividade criativa fortemente embasada em precedentes.

A tentativa de sobrepor os condicionantes que são considerados incontornáveis no processo de projeto arquitetônico, auxilia a "descontextualização momentânea do problema, a partir da qual torna-se então possível realizar cruzamentos de contextos propícios à geração de soluções arquitetônicas potencialmente mais criativas" (LASSANCE; TAVARES FILHO, 2009). Contudo, este não é um trabalho fácil, deve se desenvolver uma desconstrução crítica dos preconceitos inerentes a cada participante e te obrigar a pensar o processo de projeto de outra forma.

O projetista começou a desenvolver, ao longo dos anos, um perfil mais investigativo quanto a questões sociais, econômicas e tecnológicas. Então o processo de projeto demanda uma ação de busca por característica e informações de relevância do contexto, do futuro usuário do espaço projetado e suas necessidades, e esta procura por mais conhecimento pode se transformar em uma ação criativa. Com um mercado de trabalho cada vez mais exigente, cobra-se do arquiteto mais eficiência, qualidade e criatividade para solucionar novos problemas. Wechsler (2002) complementa:

\begin{abstract}
"O momento nos parece propício para a investigação da criatividade no Brasil, na medida em que já observamos a sua menção como algo desejável nos mais diversos ambientes e para as mais diferentes finalidades. A conceituação da criatividade está agora aliada ao funcionamento sadio do indivíduo ou a uma dinâmica de saúde mental, sendo, portanto, importante procurar o seu desenvolvimento. Cabe aos pesquisadores encontrar formas de identificar este construto, de forma ampla e multidimensional, afim de permitir que esta informação seja utilizada para colaborar na realização pessoal e profissional do indivíduo" (WECHSLER, 1998, p98).
\end{abstract}

Para o projetista, ações para aprimorar seu processo de projeto de forma mais criativa são a ampliação do seu repertório, melhor organização do projeto, exploração de múltiplas soluções e melhor compreensão das questões de projeto (BIANCHI, 2008). Ele conseguirá levar esse conhecimento para a vida profissional, isso terá um impacto positivo no resultado final dos projetos desenvolvidos por ele e consequentemente será um retorno a sociedade.

Os autores Mann, Ó Cathain (2001) incentivam o uso de um método que contribui com a geração de ideias de qualidade em menos tempo, eles usam as rampas como exemplo, e as consideram soluções inconvenientes para a maioria dos usuários, incluindo aqueles as quais são destinadas, pois requer grande esforço físico do usuário, além da inconveniência do ponto de vista estético, e lançam diversas alternativas para tal.

Em especial em arquitetura, o processo de projeto não possui uma ordem ou diretrizes rígidas ou universais entre os profissionais, além de ser complexo e pouco externado, apesar de que ainda conseguem ser atestados procedimentos comuns a vários projetistas (KOWALTOWSKI, 2006). Muitos autores já tentaram mapear os processos, apesar das diferenças entre os resultados, a ideia comum é que "se compõem de uma sequência de atividades distintas e identificáveis que ocorrem numa ordem previsível e com uma lógica identificável" (LAWSON, 2011).

O processo de projeto pode ser um processo criativo. Para Csikszentmihalyi (1997), o processo criativo é a interação entre uma pessoa, o campo e o domínio. A pessoa é o indivíduo criativo, o 


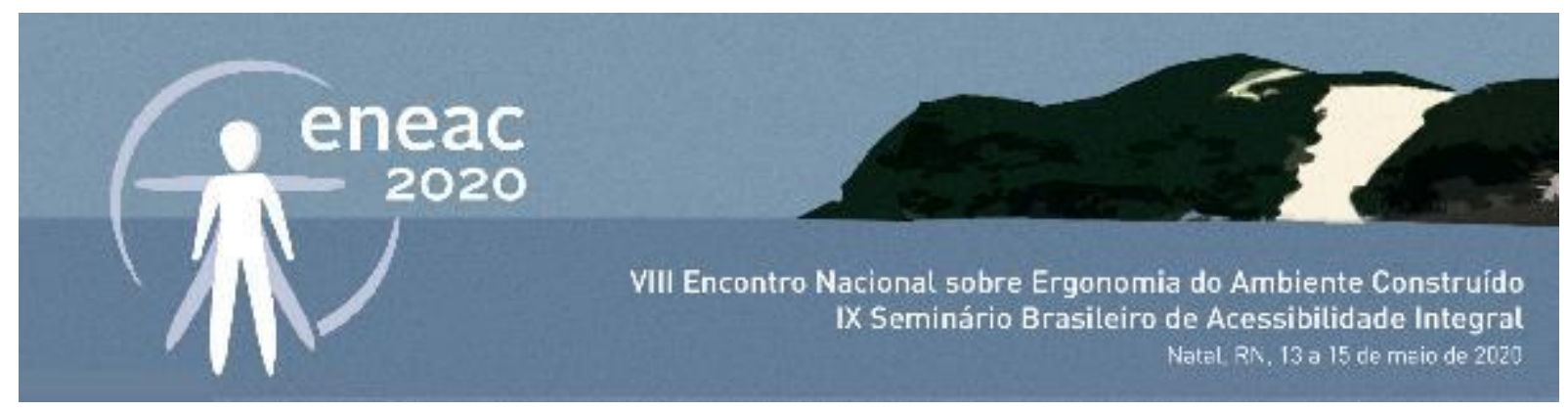

campo seria o grupo que avalia se o resultado é criativo e o domínio é o conjunto de conhecimentos que foi incorporado e considerado relevante.

Kneller (1965, apud LAWSON, 2011 p. 144) defende que o consenso geral é que podemos identificar até cinco fases, um momento inicial que ele chama de "primeira noção", depois "preparação", "incubação", "inspiração" e "verificação". A "primeira noção" é reconhecer que o problema existe e comprometer-se a resolve-lo, a etapa de "preparação" é a investigação sobre o objeto para se familiarizar com o problema, a próxima fase de "incubação" é para conexão de ideias e estudo das soluções, a fase de "iluminação" é para a resolução do problema e surgimento de ideias que serão trabalhadas no resultado final, e a última fase "verificação" é a revisão e análise do que foi idealizado. Estas etapas ajudam o projetista a criar uma intimidade maior com o tema.

\section{ACESSÍVEL E CRIATIVO}

O processo de projeto de arquitetura é composto por etapas que normalmente segue uma linha de decisão de escolhas projetuais que vão adentrando fases de maior detalhamento e especificações ao longo da criação. Dependendo de cada projetista, as normas vigentes, de modo geral, podem entrar em diferentes fases do processo, como também a NBR 9050 de Acessibilidade.

Muitos autores já tentaram mapear o processo de projeto de projetistas, existem várias análises que em resumo descrevem que "os projetistas têm de reunir informações sobre o problema, estudá-lo, imaginar uma solução e desenhá-la" (LAWSON, 2011), mas não necessariamente nesta ordem. De modo geral, os projetistas traçam as etapas do processo e tendem a segui-las de modo sequencial, mas, caso necessário, voltam para as ações anteriores.

Lawson (2011) exemplifica um mapeamento chamado 'Plano de Trabalho' que foi detalhado no 'Manual de Administração e Prática Arquitetônica'. Este é separado em doze etapas descritos em uma linha de ação lógica sequencial: primórdios, viabilidade, linhas gerais da proposta, projeto esquemático, projeto detalhado, informações sobre a produção, quantidade de materiais, propostas de orçamento, planejamento de projeto, operações no local, término e reavaliação. Estas etapas se assemelham com o processo de projeto de vários profissionais. O questionamento aqui levantado é em qual dessas etapas entraria o estudo da norma NBR 9050 e os primeiros pensamentos e soluções para sua implementação em cada projeto.

Dependendo da fase que as diretrizes da norma passam a ser um elemento de influência no processo de concepção do projeto, eles podem gerar resultados finais diferentes. Elas podem estar presentes nas primeiras etapas que, geralmente, são mais abstratas e conceituais, ou serem pensadas apenas nas etapas finais de detalhamento de projeto executivo. Cada projetista desenvolve seu método e seu processo de projeto, porém, observa-se que um projeto concebido aplicando as normas vigentes no início da sua concepção gera um produto e, consequentemente, um processo mais eficiente:

“Em um processo de projeto arquitetônico completo, verificamos um crescimento paralelo dos níveis de complexidade das fases do projeto e do compromisso com as soluções técnico-construtivas adotadas, o que significa que, quanto mais avançado o desenvolvimento, maior o esforço despendido numa eventual mudança de parâmetros e soluções. Isso tem levado, recentemente, ao deslocamento das pesquisas das 


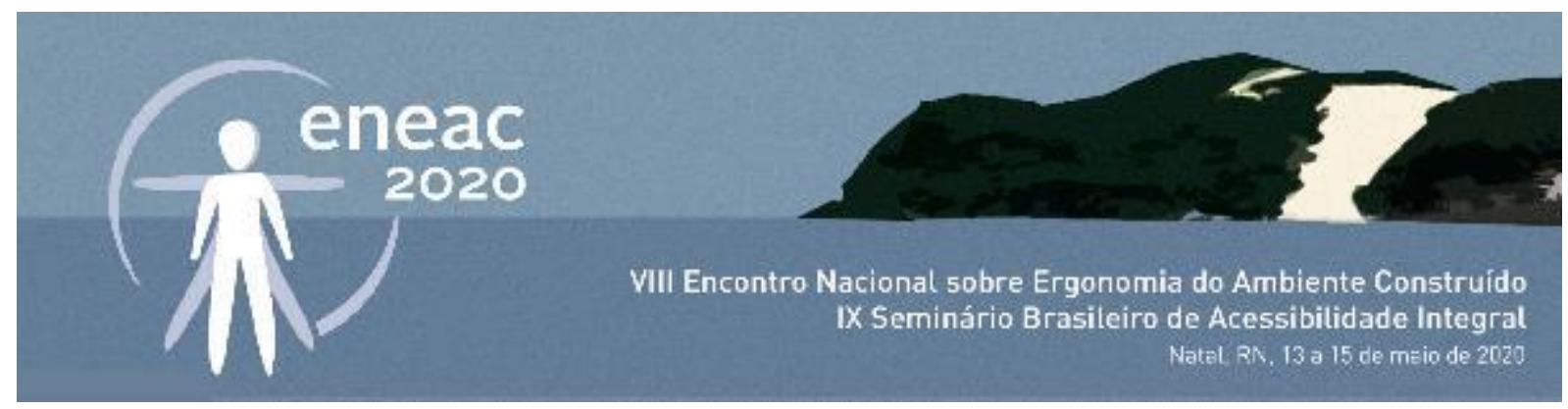

etapas finais do processo de projeto (desenvolvimento, detalhamento, simulação e construção de protótipos) para pesquisas focadas nas etapas iniciais (definição do produto, planejamento e projeto conceitual), onde os níveis de abstração são maiores. " (KIATAKE, 2004)

O processo criativo é enriquecido conforme o nível de conhecimento e a familiaridade que o projetista possui do tema:

"A qualidade do projeto depende substancialmente de conhecimentos e experiências adquiridas pelo profissional e, sobretudo, de sua capacidade de aplicá-los criativamente. Sua competência e criatividade residem na habilidade de retomar seus conhecimentos armazenados na memória e aplicá-los em uma nova situação. " (FLORIO; TAGLIARE, 2009)

Sendo assim, quanto mais os projetistas conhecerem as diretrizes das normas vigentes maior será a sua maleabilidade em trabalhar soluções aos problemas do projeto alcançando resultados mais criativos.

A falta de conhecimento aprofundado do que a norma explicita leva a entender que ela impõe regras a serem seguidas, onde na verdade ela pode se transformar em um livro de sugestões de soluções projetuais acessíveis. Quanto mais se estuda ou se entende o objetivo de cada recomendação da norma, consegue-se trabalhar ao longo do processo para chegar em resultados finais diferentes e não necessariamente a reprodução dos parâmetros ilustrados.

"No momento em que uma norma passa a balizar o desenho do arquiteto pela simples incorporaça de dimensões, geometrias e topologias, torna-se necessário ponderar sobre o entendimento dos conceitos que fundamentam a lei. Em geral, a ponderação sobre os conceitos, e não sobre as soluções, pode conduzir a inovações. " (KIATAKE; PETRECHE, 2008)

O maior contato dos projetistas com a norma, os daria uma bagagem maior para aplicar os parâmetros técnicos e incluir, com mais facilidade, esses critérios na concepção do partido do projeto. Sendo assim, a acessibilidade deixaria de entrar no projeto como um elemento de adaptação para a adequação nas normas vigentes e passaria a ser concebida desde o início sem deixar de lado aspectos estéticos e de funcionalidade. A NBR 9050 traz os conceitos de acessibilidade, Desenho Universal, deficiência e restrição, e "a importância de estudar esses conceitos está no conhecimento dos problemas que a NBR 9050 pretende solucionar. Acredita-se que quanto maior o conhecimento do problema, mais variadas e bem-sucedidas serão as soluções" (MORAES, 2007).

A forma como a norma técnica foi estruturada muitas vezes é visto como um elemento que engessa a concepção do projeto. Sua estruturação de tópicos e exigências muitas vezes são desconhecidas pelos projetistas e uma leitura literal da mesma acaba produzindo soluções segregadoras, inviabilizando a concepção de espaços que proporcionem bem-estar para todos os usuários e que sejam ainda inclusivos (LEITE,2016).

A dificuldade da relação entre o profissional e a norma é especialmente visível no mercado de trabalho. Existe uma dificuldade de resolução de casos especialmente quando não estão contemplados (detalhados) na norma, onde apenas o conhecimento pessoal do arquiteto resolveria o caso. Os órgãos, que regulam a eficácia do cumprimento da norma, trabalham muitas vezes auxiliando os arquitetos a alcançarem soluções projetuais de aplicação dos preceitos da norma: 


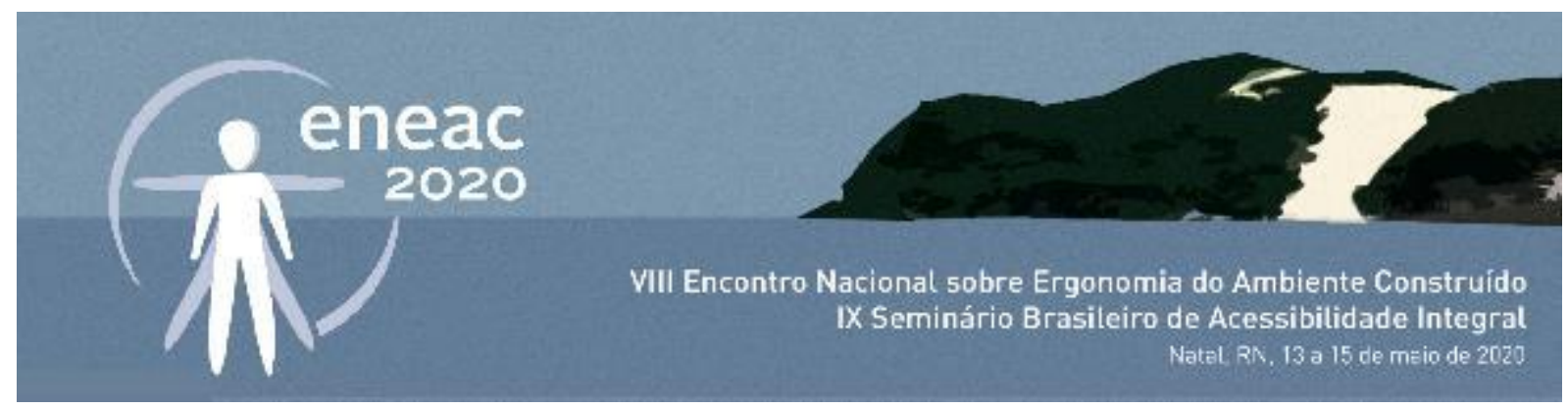

“Partindo do princípio de que para criar boas soluções é necessário conhecer o problema, acredita-se que no Brasil haja uma dificuldade na relação entre o profissional e a norma. Dessa forma, mesmo tendo a NBR 9050 em mãos, muitos profissionais não sabem o porquê de determinado parâmetro técnico ou determinação e, consequentemente, não avaliam quais os reflexos que determinados elementos terão quando implantados ou edificados no ambiente." (MORAES, 2007).

Levantamos o questionamento se estas normas limitam o processo criativo dos profissionais ou eles que se limitam ao o que elas sugerem. Tanto a NBR 9050 é excessivamente direta e técnica, como também, a falta de familiaridade e conhecimento dos projetistas com ela e com o tema de acessibilidade, direcionam para as soluções dos problemas de forma pouco criativa.

\section{CONSIDERAÇÕES FINAIS}

Existe uma falta de intimidade entre a maioria dos profissionais e estudantes de arquitetura com a norma de acessibilidade, NBR 9050. Atualmente, o tema é amplamente discutido em vários meios, contudo, em sua maioria, a população não é ciente da importância da igualdade de acesso das pessoas com deficiência e/ou mobilidade reduzida e falta aos projetistas buscarem mais informações para aprimorar seus conhecimentos e aplicabilidade destes no seu processo de projeto. Assim, transformando isso em soluções projetuais possivelmente mais criativas que agreguem funcionalidade e estética, sem se transformar em mais uma cópia dos parâmetros descritos nas normas.

A estruturação da NBR 9050 e a compatibilização necessária com cada uma das normas vigentes é outro fator que dificulta ainda mais o processo de concepção do projeto o que acarreta em aplicações literais dos itens das normas ou em soluções equivocadas de projetos.

Aliado a esses dois fatores podemos destacar ainda a importância das etapas de concepção do projeto de arquitetura. Os projetistas deveriam aplicar os preceitos de desenho universal desde o princípio do processo projetual, dessa forma, ele pode alcançar soluções de projetos mais bem pensadas e idealizadas ao longo das etapas, e possivelmente mais criativas, não aparecendo de forma engessada como apresentada nas normas vigentes ou implantada grosseiramente no resultado final.

Quanto mais esse tema é explorado com o empenho de se alcançar novas soluções, valorizamos o usuário com deficiência e/ou mobilidade reduzida, o damos atenção e melhoramos sua qualidade de vida. Isso também é refletido diretamente na qualidade do projeto apresentando, assim com soluções melhor resolvidas, funções de uso e estética bem definidos e bem aproveitados, seja nas edificações, mobiliário, espaços e equipamentos urbanos.

Para que estas discussões tenham uma fundamentação mais rica em dados, podem ser realizados estudos de campo e pesquisas com estudantes e arquitetos acerca dos temas, acessibilidade e processo criativo. Estas pesquisas buscariam entender como se estabelecem seus processos de projeto, em que momento se aplicam os parâmetros da NBR 9050, quais são suas familiaridades e experiências com ela, e qual a relação da norma com as soluções de projetos, considerando que estas alcançam resultados criativos, do ponto de vista do projetista.

\section{REFERÊNCIAS}

ABNT - Associação Brasileira de Normas Técnicas. NBR 9050- Acessibilidade a edificações, mobiliário, espaços e equipamentos urbanos. Rio de Janeiro: 2015.

ALENCAR. E. S. A gerência da criatividade - abrindo as janelas para a criatividade pessoal e nas organizações. São 


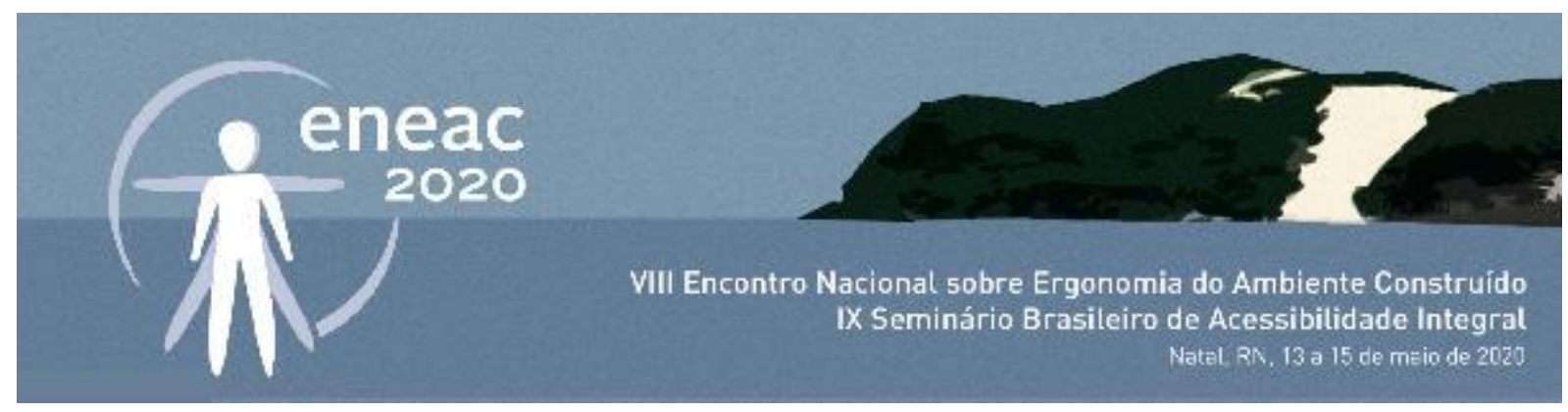

Paulo: Makron Books, 1996.

ALENCAR, E. L.S.; FLEITH, D. M. S. Criatividade: múltiplas perspectivas. Brasília: EdUNB, 2009.

BARKI, Jose. O aprendizado do fazer. In: Beatriz Santos de Oliveira; Guilherme Lassance; Gustavo Rocha-Peixoto; Laís Bronstein. (Org.). Leituras em teoria da arquitetura. 1ed.: , 2009, v. 1, p. 114-127.

BIANCHI, G. Métodos para estímulo à criatividade e sua aplicação em arquitetura. 2008. Tese (Mestrado em Engenharia Civil na Área de Concentração de Arquitetura e Construção) - Universidade Estadual de Campinas, Campinas, São Paulo.

BRASIL, Presidência da República. Lei No 13.146. Lei Brasileira de Inclusão.2015. Disponível em: <http://www.planalto.gov.br/ccivil_03/_ato2015-2018/2015/lei/l13146.htm>. Acesso em: 03 fevereiro 2020.

BRASIL. Constituição (1988). Constituição da República Federativa do Brasil. DF: Senado Federal, 1988. Disponível em: < http://www.planalto.gov.br/ccivil_03/constituicao/constituicao.htm>. Acesso em: 03 fevereiro 2020.

CSIKSZENTMIHALYI, M. (1996). Creativity: Flow and the psychology of discovery and invention. New York: Harper Collins.

ELALI, G.A. Um sistema para avaliação da acessibilidade em edificações do Campus Central da UFRN. (2004). Disponível em: <arquivos.info.ufrn.br>. Acesso em: 03 fevereiro 2020.

FLORIO, Wilson; TAGLIARI, Ana. Projeto, criatividade e metáfora. Arquitetura Revista - Vol. 5, n²:92-110 (julho/dezembro 2009).

GERO, John S; MAHER, M. L. Modeling Creativity and Knowlegde-based Creative Design. Hilldales, New Jersey, 1993.

IBGE - Instituto Brasileiro de Geografia e Estatística. Censo demográfico 2010: famílias e domicílios. Rio de Janeiro, 2010. 203f.

KIATAKE, Marly. Modelo de Suporte ao Projeto Criativo em Arquitetura: uma Aplicação da TRIZ - Teoria da Solução Inventiva de Problemas. São Paulo, 2004. Dissertação (mestrado em engenharia) - Escola Politécnica da Universidade de São Paulo. Departamento de Engenharia de Construção Civil.

KIATAKE, Marly; PETRECHE, João Roberto Diego. Criatividade e Inovação e Projetos Arquitetônicos Adaptados à Acessibilidade. 2008. Disponível em: http://www.usp.br/nutau/CD/38.pdf . Acesso em: 28 jan 2020.

KOWALTOWSKI, D. C. C. K. et al. Reflexão Sobre Metodologias de Projeto Arquitetônico. Ambiente Construído, Porto Alegre, v. 6, n. 2, p. 7-19, abr./jun. 2006a.

LASSANCE, G.; TAVARES FILHO, A. C. A Pertinência do Impertinente: Um Olhar Inusitado sobre a Concepção Arquitetônica. IV Projetar 2009. São Paulo, Brasil. Outubro 2009.

LAWSON, Bryan. Como arquitetos e designers pensam. São Paulo: Oficina de Textos, 2011.

LEITE, Mariana de Azevêdo de Lima. A NBR 9050 e o design universal: um estudo sobre o banheiro. 2016. $179 f$. Dissertação (mestrado) Universidade Federal do Rio Grande do Norte. Centro de Tecnologia. Programa de Pós Graduação em Arquitetura e Urbanismo. Natal, 2016.

LUBART, T. Psicologia da criatividade. Porto Alegre: ARTMED, 2007.

MANN, D.; Ó CATHÁ IN, C. 2001. Apud: KIATAKE, Marly. Modelo de Suporte ao Projeto Criativo em Arquitetura: uma Aplicação da TRIZ - Teoria da Solução Inventiva de Problemas. 2004. Dissertação (Mestrado em Engenharia) - Escola Politécnica da Universidade de São Paulo, São Paulo.

MARTÍNEZ, A.C. Ensaio sobre o projeto. Brasília: UnB, 2000.

MORAES, Miguel Correia de. Acessibilidade no Brasil: Análise da NBR 9050. 2007. 173 f. Dissertação (Mestrado em Arquitetura e Urbanismo) - Universidade Federal de Santa Catarina, Florianópolis, 2007.

SANTOS, Maria Selma Barboza dos. Da formação à Prática Docente: Uma Habilidade Criativamente Inovadora. IV CONEDU - Congresso Nacional de Educação, 2017.

UNESCO/UIA. Carta para Formação dos Arquitetos. Edição Revisada 2011. Disponível em: <http://www.abea.org.br/wpcontent/uploads/2013/03/Carta-UNESCO-UIA-2011.pdf>. Acesso em: 19 set. 2016. 


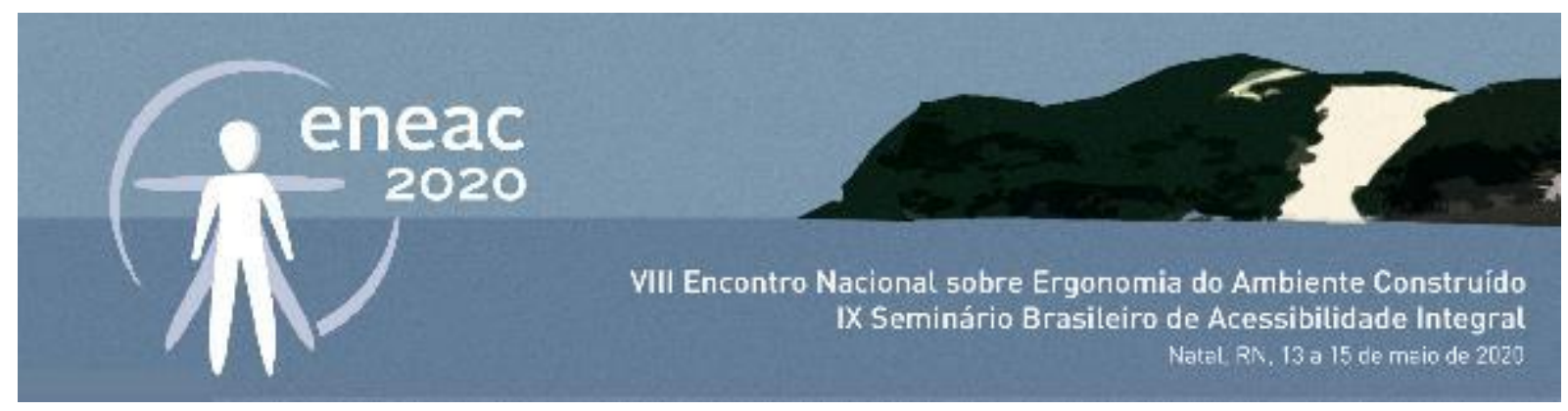

WECHSLER, Muglia. Avaliação multidimensional da criatividade: uma realidade necessária. Psicologia Escolar e Educacional, 1998, p.89-99.

\section{NOTAS}

i É uma interjeição que significa "encontrei" ou "descobri" e ficou conhecida pelo episódio protagonizado por Arquimedes de Siracusa (287 a.C. - 212 a.C.) quando conseguiu resolver um complexo problema para o rei Hierão. 